\title{
Fasciola hepatica: ecologia e trajetória histórico-geográfica pelo Brasil
}

\section{Darlan Morais Oliveira ${ }^{1}$ e Patrícia Oliveira Resende ${ }^{2}$}

1 Pós-Graduando Lato Sensu em Análises Clínicas pela Unyleya e graduado em Ciências Biológicas pelo Instituto de Ensino Superior do Sul do Maranhão, Brasil. E-mail: darlan_morais@hotmail.com

2 Graduada em Licenciatura em Ciências Biológicas pelo Instituto de Ensino Superior do Sul do Maranhão, Brasil. E-mail: patriciaoresende@gmail.com

Resumo: Este trabalho objetivou sintetizar a partir de uma revisão bibliográfica todo percurso histórico e geográfico da Fasciola hepatica pelo Brasil, correlacionando os fatos com seu ciclo de vida. A literatura consultada revela que $F$. hepatica é um parasita que necessita obrigatoriamente de dois hospedeiros para completar seu ciclo de vida: o caramujo Lymnaea, hospedeiro intermediário- e o hospedeiro definitivo, que pode ser de diversas espécies de vertebrados, inclusive o homem. Com tantos hospedeiros, o parasita vem sendo continuamente transportado para ambientes com temperatura moderadas e disponibilidade de água, favoráveis ao seu desenvolvimento. Sua história no Brasil inicia-se em 1918, na região Sul. Nas décadas seguintes, esse trematódeo se expandiu geograficamente até alcançar a região Norte. Logo, conclui-se que há perspectivas da F. hepatica atingir todo o território brasileiro nos próximos anos. Palavras-chave: Fasciolose. Hospedeiro. Lymnaea.

Fasciola hepatica: ecology and historical-geographical trajectory in Brazil

Abstract: This work aimed to synthesize from a bibliographical review all historical and geographic trajectory of Fasciola hepatica by Brazil, correlating facts with its life cycle. The literature consulted reveals $\mathrm{F}$. hepatica is a parasite that requires two hosts to complete its life cycle, the intermediate host being the Lymnaea snail and the definitive hosts, several species of vertebrates including man. With so many hosts the parasite has been continuously transported to environments favorable to its development, which includes moderate temperature and water availability. Its history in Brazil begins in 1918 in the South, over the years this trematódeo has expanded geographically until reaching the North region in the last decades. Therefore, it is concluded that there are prospects for $F$. hepatica to reach the entire Brazilian territory in the coming years.

Keywords: Fasciolose. Host. Lymnaea.

\section{INTRODUÇÃO}

Fasciola hepatica é um parasita pertencente ao filo Platyhelminthes por ser acelomado, achatado dorsoventralmente, com sistema digestório incompleto, sendo desprovido de aparelhos respiratório, circulatório, exo ou endoesqueleto; incluído na classe Trematoda por serem parasitas nãosegmentados, e ainda inseridos na subclasse Digenea por necessitar de dois hospedei- ros para completar seu ciclo de vida (NEVES; MELO; LINARDI, 2005)

A trajetória do $F$. hepatica no mundo é tão antiga quanto a história da humanidade. Achados paleontológicos na Alemanha, datados de 3.000 a.C., revelam a presença de ovos desse trematódeo em restos humanos e de bovinos, mostrando que já era encontrado no velho mundo (BRAVO, 2007). Na história, o primeiro registro de $F$. hepatica teria se dado no século IX no Tra- 
tado de Saúde Animal do Mundo Árabe, quando é citada "uma doença de fígado" em ovinos, sendo o primeiro trematódeo a ter seu ciclo de vida descrito em 1882 na Alemanha (MENDES, 2007).

De acordo com a Parasitologia, o F. hepatica pode ser enquadrado como parasita heteroxênico, eurixenico e acidental, portanto possui diversos hospedeiros de diferentes espécies (NEVES; MELO; LINARDI, 2005), deste modo, são suscetíveis de serem transportados por inúmeras espécies de animais para as mais diferentes regiões do planeta. Dessa forma, esse parasita alcançou uma distribuição geográfica quase cosmopolita, podendo ser encontrado em áreas de todos os continentes, exceto a Antártida (GOMES, 2006). Atualmente, esse parasita encontra-se mundialmente disseminado, albergando rebanhos e humanos. De acordo com a literatura científica, a infecção humana varia entre 2,4 milhões de pessoas (ALVES; MARTINS, 2013) a $17 \mathrm{mi}-$ Ihões (BRAVO, 2007) em 40 países (GOMES, 2006). Entre os países atingidos pelo trematódeo está o Brasil, que acumula uma história recente no contexto mundial desse organismo. Portanto, realizou-se este estudo bibliográfico com o objetivo de sintetizar a história e distribuição geográfica da $F$. hepatica no país, correlacionando com o ciclo biológico do mesmo.

Para alcançar o objetivo foi feito uma busca bibliográfica a partir de seleção de produções científicas coletadas do domínio eletrônico Scielo, no qual se utilizou os principais termos indexadores: "Fasciola hepática" + Brasil + história + distribuição, dentre outros. Além de pesquisas em sites de relevância veterinária e livros de parasitologia. O trabalho encontra-se estruturado em apenas um capítulo sintetizando todos os principais fatos encontrados na literatura, além das conclusões.

\section{DESENVOLVIMENTO}

O ciclo de vida de F. hepatica consiste em seis etapas após a eclosão do ovo, passando pelos estágios larvares de miracídio, esporocisto, rédia, cercária e metacercária e finalmente a forma adulta que produz ovos. Esse complexo ciclo só pode ocorrer se houver condições favoráveis, principalmente diante de temperaturas moderadas.

Temperaturas entre $10^{\circ} \mathrm{C}$ a $30^{\circ} \mathrm{C} ; \mathrm{pH} 7$ com variações entre 4,2 a 9,0; ambiente aeróbico e presença de água são condições necessárias para o desenvolvimento embrionário e eclosão do ovo com consequente emissão da larva ciliada denominada miracídio que mede $220-500 \mu \mathrm{m}$ por $70-80 \mu \mathrm{m}$, com vida útil de 8 a 10 horas em um ambiente aquático favorável, onde a mesma nada até encontrar um hospedeiro intermediário (COSTA, 2010).

A $F$. hepatica tem como hospedeiro intermediário caramujos do gênero Lymnaea, sendo o mais comum no Brasil é a espécie Lymnaea columela. Contudo, o miracídio pode penetrar em diversas espécies de moluscos aquáticos, ocasionado a morte imediata da larva se esta penetrar no hospedeiro errado (NEVES, 2005). Após penetração no caramujo, o miracídio perde os cílios, migra através dos vasos sanguíneos ou canais linfáticos até à região periesofágica, transforma-se em esporocisto e depois se desenvolve na hepatopâncreas até atingir 600 a $700 \mu \mathrm{m}$ (COSTA, 2010). Do desenvolvimento dos esporocistos originam-se as rédias que medem cerca de 1 a $3 \mathrm{~mm}$ de comprimento e tem alguma capacidade de movimentação, estas dão origem às cercá- 
rias, que se assemelham a um girino e podem ter $300 \mu \mathrm{m}$ de diâmetro e $600 \mu \mathrm{m}$ de cauda (COSTA, 2010). Após 7 a 8 semanas da infecção, as cercárias abandonam o caracol devido à elevação da temperatura e luminosidade. No entanto, a emissão não ocorre abaixo dos $12^{\circ} \mathrm{C}$ nem acima dos $25^{\circ}$ C. Após a emissão, as cercárias perdem a cauda e fixam-se por meio da ventosa ventral a plantas, encistando-se e transformando-se em metacercárias (COSTA, 2010). As metacercárias possuem 0.20 a $0.25 \mathrm{~mm}$ e são semelhantes a grãos de areia, sendo esta a forma infectante para o hospedeiro definitivo. Elas conseguem sobreviver no ambiente exterior sob certas condições, tolerando melhor o frio (abaixo de $-10^{\circ} \mathrm{C}$ ), mas são bastante sensíveis ao calor e à dessecação (COSTA, 2010).

Nota-se que a água, tempo e temperatura são fatores preponderantes para o desenvolvimento larval da F. hepatica, embora alguns pesquisadores divirjam sobre alguns fatos. Como exemplo, cita-se o trabaIho de Neves (2005) que discorda de Costa (2010) ao mencionar, por exemplo, que a faixa de temperatura para o desenvolvimento embrionário é de $25-30^{\circ} \mathrm{C}$; que a vida média do mirácidio é de 6 horas; que a emissão das cercárias do corpo do molusco ocorre à temperatura de $26^{\circ} \mathrm{C}$ e que também a metacercária tolera temperatura mínima de $5^{\circ} \mathrm{C}$. Possivelmente, as divergências entre os autores devam-se às diferenças ecológicas, ambientais e climáticas entre as localidades estudadas. A publicação de Costa (2010) é referente ao ciclo de vida da F. hepatica em Portugal, baseados em estudos realizados naquele país, enquanto que a publicação de Neves (2005) faz referência a fatos ocorridos no Brasil, a partir da chegada do trematódeo no país.
Desse modo, considerando as condições naturais muito distintas entre o Brasil e Portugal, sugere-se que a $F$. hepatica esteja se tornando evolutivamente adaptável a diferentes condições climáticas. Todavia, embora haja diferença entre medidas exatas de temperatura, é notório na literatura que o desenvolvimento larval do F. hepatica se dê em temperaturas amenas, não excedendo $30^{\circ} \mathrm{C}$, mescladas ainda a disponibilidade hídrica e periodicidade, ao passo que altas temperaturas e ressecamento impedem tal desenvolvimento. Este fato se torna uma possível justificativa para a ocorrência predominante, mas não exclusiva, desse parasita em regiões frias ou temperadas. As maiores prevalências deste helminto no mundo se dão na região dos Andes, Cuba, Oriente Médio e Europa Ocidental, enquanto que no Brasil predominam-se na porção sul do país (SEHABIAGUE, 2010).

Ainda discorrendo sobre o ciclo biológico deste organismo, o processo de desenvolvimento não se encerra com as formações de metacercárias, pois a partir destas dá-se origem a outro processo do ciclo de vida do trematódeo, conhecida por alguns autores por fase intramamífero (COSTA, 2010), tendo em vista que a maioria dos hospedeiros definitivos do verme são mamíferos.

A infecção natural do hospedeiro definitivo ocorre por meio da ingestão das metacercárias contidas em água ou vegetais contaminados. Uma vez instalado no interior do hospedeiro definitivo, as metacercárias que não são eliminadas nas fezes, desencistam-se, atravessam a parede do intestino, alcançam a cavidade peritoneal e chegam ao fígado. Neste órgão, as formas já adultas atingem a maturidade sexual em quatro semanas e começam a eliminar até 20.000 ovos/dia para a bílis e depois para as fezes, 
reiniciando o ciclo (COSTA, 2010) o qual é representado na Figura 1, a seguir:

Figura 1: Ciclo de biológico da Fasciola hepática Figure 1: Biological cycle of Fasciola hepatica

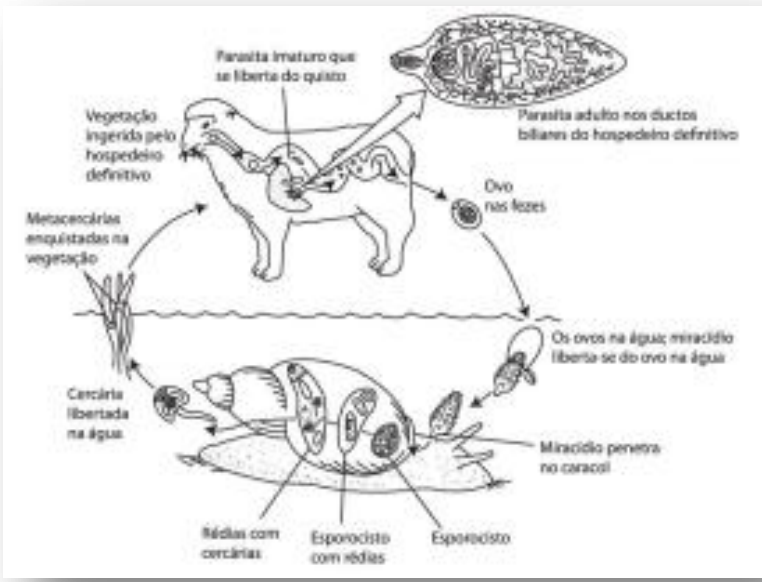

Fonte: Roberts \& Janovy (2009) apud Levy et al. (2017)

As lesões causadas pelo deslocamento do verme no fígado do hospedeiro definitivo acarretam na enfermidade denominada fasciolose que consiste basicamente na inflamação do fígado e ductos biliares (NEVES, 2005), sendo uma das principais doenças do gado bovino e ovino no mundo, enquanto que no homem embora seja menos severa, ela é considerada pela Organização Mundial da Saúde (OMS) como doença tropical negligenciada, emergente e grave problema de saúde pública em alguns países (SEHABIAGUE, 2010).

A F. hepatica tem como hospedeiros definitivos bovinos, ovinos e humanos podendo também infectar outros ruminantes como os caprinos, zebuínos, bubalinos, etc; carnívoros, suínos e equinos, com menor frequência; mamíferos selvagens como os logomorfos e cervídeos; roedores; aves (COSTA, 2010) e camelídeos (LEVY; MATEUS; PINTO, 2017).

Testes em laboratório demonstraram que o parasita se adapta bem no organismo do sagui (Callithrix penicillata), podendo este primata servir de modelo experimental, além do que, primatas do gênero Macaca e o marsupial Vombatus hirsutus também demonstraram suscetibilidade para serem infectados (MENDES, 2006).

Diante da gama de possíveis hospedeiros definitivos deste platelminto, percebe-se o quanto ele é ecologicamente versátil e adaptável, e isso favorece sua expansão geográfica de ocorrência, que por sua vez implica no surgimento de surtos de fasciolose tanto em rebanhos quanto em humanos, gerando uma preocupação econômica e de saúde pública no mundo.

Nessa conjuntura, se por um lado a temperatura constitui um fator limitante para a distribuição e expansão ecológica do $F$. hepatica, por outro, a diversidade de hospedeiros possibilita a disseminação do helminto por diversas regiões do mundo, tanto pelo fato de haver grande número de espécies de hospedeiros definitivos, quanto pela ampla distribuição geográfica do hospedeiro intermediário.

Provavelmente, em virtude da versatilidade deste trematódeo digenético, ele hoje pode ser encontrado em várias partes do mundo, havendo ocorrências em quase totalidade da Europa, Ásia e Américas, países do Norte da África, zonas frias da África do Sul, Austrália e Nova Zelândia (LEVY; MATEUS; PINTO, 2017).

Nesse contexto, anteriormente descrito, na medida em que parasitas são transportados por seus hospedeiros, sejam eles homens ou animais, através das migrações, com o advento dos transportes aéreo e marítimo, muitas espécies de parasitas invadiram o Brasil (CHARME; BATOULI-SANTOS; BRANDÃO, 2008). 
No caso em especial da F. hepatica, sua primeira notificação no Brasil ocorreu no ano de 1918, numa infecção de bovinos e ovinos no Estado do Rio Grande do Sul (NEVES; MELO; LINARDI, 2005) poucos anos após, em 1921, Adolfo Lutz fez o primeiro registro de caramujos Lymnea cubensis infectados por $F$. hepática no município de Três Rios, Estado do Rio de Janeiro, e em 1930 a 1932 o parasito já estava tão disseminado no Rio Grande do Sul que dados de um frigorífico apontavam que $10,6 \%$ dos animais abatidos estavam infectados, enquanto que em 1940 foi publicado o primeiro caso em Minas Gerais, de um bovino infectado no município de Viçosa (COELHO, 2007).

Após quarenta anos dos primeiros diagnósticos de fasciolose animal, em 1958 foi detectado o primeiro caso de fasciolose humana em uma criança de três anos de idade em Campo Grande, Estado do Mato Grosso do Sul. No ano de 1965 foram publicados fatos sobre os sete primeiros casos de fasciolose humana no Vale do Paraíba, São Paulo, em sequência mais um caso em 1967, em Cornélio Procópio, Estado do Paraná (CORREA; FLEURY, 1971). Os relatos de fasciolose humana coincidem com a grande ocorrência de fasciolose animal nos Estados citados, uma vez que a doença após ter ficado restrita nos Estados do Sul do Brasil, se expandiu para o Sudeste e Centro-Oeste, alcançando o Vale do Paraíba em São Paulo, e na sequência atingiu o Mato Grosso do Sul, espalhando-se por Minas Gerais (NEVES; MELO; LINARDI, 2005).

Atualmente no Brasil, as áreas mais atingidas pela $F$. hepatica estão localizadas no Rio Grande do Sul, Santa Catarina, Paraná, São Paulo, sul de Minas Gerais e Rio de Janeiro (ECHEVARRIA, 2004) podendo tam- bém ser encontrada no Espírito Santo e Mato Grosso do Sul (NEVES; MELO; LINARDI, 2005) como pode ser observado na Figura 2.

Figura 2: Área endêmica da F. hepatica no Brasil Figure 2: Endemic area of $F$. hepatica in Brazil

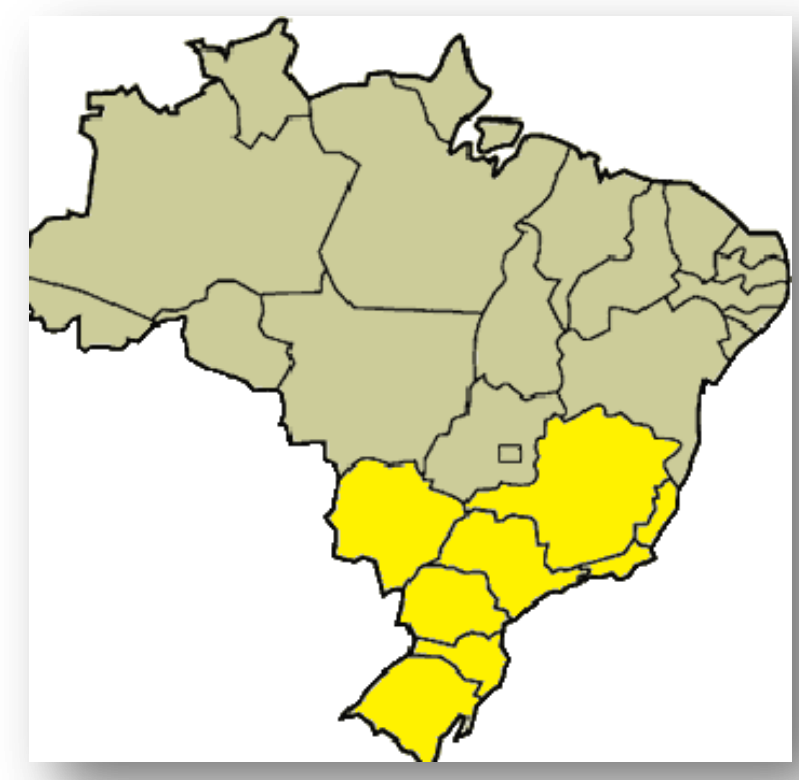

Fonte: Almeida (2010)

Pela relação de Estados descritos no parágrafo anterior, ratificam-se os argumentos anteriores que sugerem a temperatura moderada como um fator de favorecimento para o desenvolvimento do parasito, além da disponibilidade de água e do hospedeiro intermediário encontrado na localidade. Todavia, a expansão da $F$. hepatica tem demonstrado ser contínua, não se limitando à região Sul e sua migração para o Sudeste e Centro-Oeste do país não estagnou, com estudos apontando que sua migração é constante e progressiva.

Ainda na época das notificações dos primeiros casos de fasciolose humana no país, dois casos foram confirmados no Nordeste brasileiro, precisamente no município de Ilhéus na Bahia no ano de 1967 por Santos 
et al. (apud CORREA; FLEURY, 1971). A controvérsia neste fato é que as literaturas pesquisadas divergem se tais casos são autóctones, ou seja, se a infecção se deu realmente na localidade onde os pacientes habitavam.

Correa e Fleury (1971) foram alguns dos primeiros autores a se referirem às ocorrências de llhéus como casos autóctones. Posteriormente, Neves, Melo e Linardi (2005) afirmaram que os casos isolados de Ilhéus eram não-autóctones, e desse modo, o contágio pelo parasita não se deu no local onde os pacientes habitavam, podendo estes terem contraído o parasita em outro lugar. Enquanto a dúvida persiste, a há indícios na literatura de que o argumento de Neves, Melo e Linardi (2005) é o mais consistente, considerando que a disponibilidade dos caramujos limnídeos é fator primordial para a ocorrência de fasciolose. Contudo o primeiro registro de um limnídeo para o Nordeste só ocorreu em 1985 em Salvador, Estado da Bahia, cerca de dezoito anos após os casos de Ilhéus (PARAENSE, 1986). Além disso, a literatura consultada não menciona casos de fasciolose animal na Bahia. Embora Gomes (2003) mencione que houve casos isolados de fasciolose bovina na Bahia, o autor toma como base para essa afirmação a publicação de Paraense (1986), quando na verdade essa publicação trata do primeiro registro de L. columela na Bahia e não da F. hepática.

Outros indícios duvidosos do deslocamento da $F$. hepatica para áreas não endêmicas e atípicas foram relatados no Estado do Maranhão. Serra Freire (1999 apud AMARANTE, 2013) cita um registro impreciso de fasciolose em bovinos encontrados em Imperatriz, Maranhão. O autor questiona essa ocorrência, uma vez que não se sabia a origem dos animais, bem como não havia registros de caramujos limnídeos na área.

Como já discutido antes, a presença de caramujos liminídeos constitui fator determinante para o aparecimento da F. hepati$c a, \log \theta \theta$ a expansão do Lymnea pelo país sugere a expansão do trematódeo em questão.

Hospedeiros intermediários de F. hepática estão mais bem distribuídos nas regiões Sul, Sudeste e Centro-Oeste, contudo ocorrências isoladas já foram notificadas em outras regiões, sendo o segundo registro para a região Nordeste ter se dado em Campina Grande, Estado da Paraíba no ano de 1995 (ABÍLIO; WATANABE, 1998) e o terceiro e até então último registro que se tem notícia para o Nordeste provém do Estado do Ceará, no qual entre os anos de 2003 e 2006 em um estudo sobre suscetibilidade da L. columela à infecção por F. hepática realizado em Minas Gerais, foram enviados 50 caramujos desta espécie proveniente de Fortaleza, Estado do Ceará, para fins de comparação (COELHO, 2007).

Para a região Norte do Brasil, que também não é endêmica para a fasciolose, os primeiros registros de limnídeos se deram em 1983 no Estado do Amazonas, nos municípios de Bejamin Constant e Manaus, seguido pelo munícipio de Tefé em 1985 (PARAENSE, 1986) e nos últimos anos nesse Estado já foram descritos registros nas cidades de Iranduba, Careiro e Coari; além de Rio Branco, Acre e Belém, Pará (MEDEIROS et al., 2014).

Outros indícios relevantes da migração da $F$. hepatica para áreas não endêmicas é a presença de seus ovos detectados em experimentos laboratoriais, relacionado a estudos de cunho sanitário de alimentos, tais como as hortaliças. Duque et al. (2014) ao 
analisarem amostras de alface comercializados em Vitória da Conquista, Bahia, no ano de 2014 , encontraram $12,5 \%$ de amostras positivas para ovos de $F$. hepatica. De igual modo, Almeida et al. (2016) também encontrou positividade de $5,4 \%$ em amostras de alfaces comercializados em Patos, Paraíba.

Considerando que para o Estado da Bahia já foram notificados casos de fasciolose humana e que tanto na Bahia como na Paraíba confirmou-se a presença de Lymnaea em anos anteriores ao estudo de Duque et al. (2014) e Almeida et al. (2016), é considerável a possibilidade de tais ovos serem realmente do parasito em questão, indicando sua expansão nesses Estados.

Ovos de $F$. hepática também já foram observados em amostras de cebolinha coletadas entre 2006/2007 em Caruaru, Pernambuco (ESTEVES; FIGUEIRÔA, 2009) e em amostras de acelga coletadas entre 2010/2011 na cidade de Picos, Piauí (SOUSA; SILVA; GOMES, 2011). Porém, esses achados são relativamente controversos, haja vista que nessas localidades não há condições climáticas favoráveis para o ciclo de vida da $F$. hepática, e principalmente não há registro na literatura da ocorrência de Lymnaea nesses Estados.

A presença de ovos do trematódeo em diferentes regiões do país também pode se justificar pelo transporte dos ovos nas fezes de animais. Neves, Melo e Linardi (2005) afirma que a disseminação da fasciolose se deve também ao comércio de bovinos que são transportados de Sul para o Norte, com caminhões cheios de fezes contaminadas com ovos, os quais são lavados próximos a reservatórios de água. Há de se considerar ainda que nestes casos ocorridos em Estados do Nordeste, há possibilidade de enga- no ao interpretar as estruturas microscópicas, considerando que os autores não informaram nas publicações se foi aplicada alguma metodologia especifica para diagnosticar ou diferenciar os referidos ovos. A confusão é possível, pois os ovos de $F$. hepatica são muito semelhantes aos ovos de Paramphistomum sp a ponto de serem confundidos (UFF, 2015), sendo que esse último é mais claro e um pouco maior (COSTA, 2010),

O Paramphistomum sp é outro trematódeo digenético responsável por moléstias causadas em rebanhos (LAGARES, 2006), no entanto parece estar melhor distribuído pelo país do que a $F$. hepatica. Focos de ocorrência de Paramphistomum sp são comuns na região Sul (GIRÃO et al, 1999), porém, há registros em rebanhos no Ceará, Piauí e Pará (SOARES; ARAÚJO; ARAÚJO, 1993; AMARANTE, 2013).

No Estado do Pará, no estudo de Borges (2010), foram encontrados ovos de espécie de Fasciola em hortaliças comercializadas em Belém, sem que os autores determinassem se tratava da F. hepática. Todavia, considerando que no Brasil não ocorrem naturalmente outras espécies de Fasciola, então se considera o resultado deste autor como positivo para $F$. hepática. Embora este Estado não seja uma área endêmica para a doença, nos últimos anos com disseminação do hospedeiro intermediário e por consequência de seu parasita, com registro de Lymnaea em Belém (MEDEIROS, 2014). Bennema et al. (2014) menciona a ocorrência de um caso de fasciolose bovina em um município não mencionado no Pará e também Neves et al. (2011) observou fasciolose em fígados de bubalinos abatidos na região Oeste do Estado.

Também na região Norte, no Estado do 
Amazonas, comprovou-se a chegada do parasita, inicialmente pelas notificações já mencionadas de caramujos limnídeos, sendo detectados casos de fasciolose humana no ano de 2006 em Canutama (OLIVEIRA; NASCIMENTO; SANTOS, 2007).

Por fim, a literatura científica também mostra a existência de $F$. hepática para o Estado do Tocantins, também na região Norte. Aleixo et al. (2015) ao mapearem a incidência de fasciolose bovina no Brasil, tomando como base o Serviço de Inspeção Federal (SIF/MAPA), demarcaram o Tocantins com um dos Estados incidentes com casos registrados entre 2003 a 2008 conforme ilustra a Figura 3:

Figura 3: Incidência de $F$. hepatica em fígados de bovinos entre 2003 a 2008 de acordo com o SIF/MAPA.

Figure 3: Incidence of F. hepatica in cattle livers from 2003 to 2008 according to SIF / MAPA.

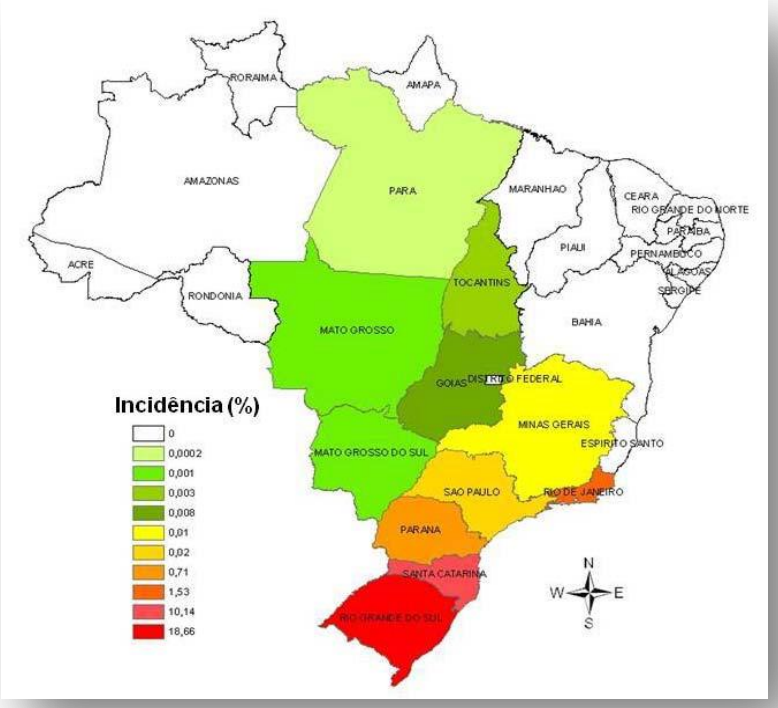

Fonte: Aleixo et al (2015)

De acordo com a figura anterior, para a época descrita, os casos de fasciolose bovina já estão presentes em todas as regiões do Brasil, exceto o Nordeste, com maior incidência para as regiões Sul e Sudeste, onde as condições climáticas são mais favoráveis para o ciclo de vida do parasita.

\section{CONCLUSÕES}

O clima é um fator limitante para o ciclo de vida e a expansão territorial da $F$. hepati$c a$, enquanto que a presença de caramujos limnídeos é um fator determinante de seu desenvolvimento e disseminação geográfica. Logo, o próprio ciclo biológico do parasita é responsável pela sua dispersão espacial.

A F. hepatica iniciou seu contexto histórico no país na região Sul nas primeiras décadas do século $X X$ e nas primeiras décadas do século XXI alcançou a região Norte, portanto sua trajetória geográfica se deu no sentido sul para norte ao longo de quase cem anos de história.

No entanto, ainda não há comprovação na literatura de ocorrências de $F$. hepática na região Nordeste, apenas fortes indícios. Também por meio deste estudo, dada às circunstâncias, observa-se que há perspectiva de que a $F$. hepática atinja todo o território nacional nos próximos anos, haja a vista a versatilidade do parasito em infectar vários vertebrados, especialmente animais de importância econômica que são continuamente transportados entre as regiões brasileiras para fins comerciais, e principalmente por ter seu hospedeiro intermediário amplamente distribuído pelo país e em contínua expansão.

Este estudo trouxe como inovação para o tema o delineamento do perfil da F. hepática no Brasil dentro de uma visão espacial e temporal, algo que é pouco abordado ou demonstrado nas publicações já existentes, contribuindo assim para formulação de mapeamentos, campanhas e projeções de me- 
didas de prevenção e controle da fasciolose animal e/ou humana.

Diante a evidente expansão da $F$. hepática pelo território brasileiro se faz necessária intervenção governamental, por meio a interação e cooperação de órgãos ligados às áreas da Saúde, Meio Ambiente, Vigilância Sanitária e Agropecuária a fim de prover maior controle de qualidade na criação, abate, comercialização e transporte de vertebrados que servem como hospedeiros definitivos do parasita, bem como promover o saneamento de quaisquer cursos ou reservatórios d'agua que possam abrigar o hospedeiro intermediário, tudo isso como possíveis medidas de controle e prevenção.

\section{REFERÊNCIAS}

ABÍLIO, F. F. P.; WATANABE, T. Ocorrência de Lymnaea columela (Gastropoda: Lymnaeidae), hospedeiro intermediário da Fasciola hepatica, para o Estado da Paraíba, Brasil. Rev. Saúde Pública. São Paulo, v. 32, n. 2, p. 184-185, abril. 1998.

ALEIXO, M. A et al. Fasciola hepatica: epidemiology, perspectives in the diagnostic and the use of geoprocessing systems for prevalence studies. Semina: Ciências Agrárias, Londrina, v. 36 , n. 3 , p. 1451-1466, maio/jun. 2015.

ALMEIDA, B. R. Malacologia dos gêneros Lymnaea e Biomphalaria na Mesorregião Sul Espírito-santense, e a avaliação de extratos de Melia azedarach, Azadirachta indica, e Cymbopogon winterianus como agentes moluscicidas. 2010. 174f. Dissertação (Mestrado em Ciências Veterinárias) Universidade Federal do Espírito Santo, Alegre, 2010.

ALMEIDA, E. M. S. M. et al. Análises parasitológicas em folhas de alface comercializa- das em supermercados da cidade de PatosPB. Temas sem Saúde, João Pessoa, v. 16, n. 3, p. 287-301, 2016.

ALVES, D. P.; MARTINS, I. V. F. Atualizações no controle parasitário da fasciolíase em bovinos. Enciclopédia Biosfera, Centro $\mathrm{Ci}$ entífico Conhecer - Goiânia, v.9, n.16; $p$ 323-351, 2013.

AMARANTE, E. E. V. G. Estudo comparativo da helmintofauna de bovinos e caprinos de criação extensiva no Semiárido Nordestino: uma análise das relações com a Saúde Pública e a conservação da biodiversidade. 2013.130f. Dissertação (Mestrado em Ciência na Área de Saúde Pública) - Escola Nacional de Saúde Pública Sergio Arouca, 2013.

BENNEMA, S. C. et al. - Fasciola hepatica in bovines in Brazil: data availability and spatial distribution. Rev. Inst. Med. Trop. Sao Paulo, v. 56, n. 1, p. 35-41, 2014.

BORGES, S. L. Frequência e diversidade de enteroparasitas veiculadas por hortaliças por hortaliças comercializadas na cidade de Belém/PA e sua relação com a sazonalidade climática. 2010. 110f. Dissertação (Mestrado em Patologia das Doenças Tropicais) - Universidade Federal do Pará, Belém, 2010.

BRAVO, T. C. Fasciola hepatica: ciclo biológico y potencial biótico. Rev Mex Patol Clin, v.54, n. 1, p. 21-27, jan-mar, 2007.

CHARME, M; BATOULI-SANTOS, A. L.; BRANDÃO, M. L. As migrações humanas e animais e a introdução de parasitas exóticos invasores que afetam a saúde humana no Brasil. Fumdhamentos. São Raimundo Nonato/PI, [s.v.], n. 07, p. 47-62. 2008.

COELHO, L. H. L. Lymnaea columella (Pulmonata: Lymnaeidae): dinâmica de populações em Itajubá, Minas Gerais, e suscetibilidade à infecção por Fasciola hepatica (Di- 
genea: Fasciolidae) em associações simpátricas e alopátricas entre parasito e hospedeiro. 2007. 112f. Tese (Doutorado em Parasitologia) - Universidade Federal de Minas Gerais, Belo Horizonte, 2007.

CORREA, M. O. A.; FLEURY, G. C. Fasciolíase hepática humana: nôvo caso autóctone. Rev. Soc. Bras. Med. Trop. v. 5, n. 5, 267270, set-out, 1971.

COSTA, A. M. C. B. Fasciolose Bovina: Aspectos clínicos e epidemiológicos no Alentejo. 2010. 102f. Dissertação (Mestrado em Medicina Veterinária) - Universidade Técnica de Lisboa, Lisboa/PT, 2010.

DUQUE, I. L. L et al. Pesquisa de ovos de helmintos e oocitos de protozoários em alfaces (Lactuca sativa) comercializadas em feiras livres e supermercados. Veterinária em Foco, Canoas, v. 11, n. 2, p. 104-111, jan/jun, 2014.

ECHEVARRIA, F. Fasciolose. Rev. Bras. Parasitol. Vet., v.13, suplemento 1, p. 100-102, 2004.

ESTEVES, F. A. M.; FIGUEIROA, E. O. Detecção de enteroparasitas em hortaliças comercializadas em feiras livres do município de Caruaru (PE). Rev. Baiana de Saúde Púb. v.33, n. 2, p.38-47, abr-jun, 2009.

GIRÃO, E. S.; LEAL, J. A.; MEDEIROS, L. P. et al. Verminose bovina. Teresina: Embrapa Meio Norte, 1999.

GOMES, F. F. Estudo e um foco de Fasciola hepatica (Linnaeus, 1758) no município de Campos dos Goytacazes, Estado do Rio De Janeiro. 2003. 68f. Dissertação (Mestrado em Produção Animal) - Universidade Estadual do Norte Fluminense, Campo dos Goytacazes, 2003.

LEVY, S.; MATEUS, T. L.; PINTO, M. V. Fasciolose. Disponível em: <http://www.agro negocios.eu/noticias/fasciolose/>. Acesso em: 30 jan. 2017.
MEDEIROS, C. et al. - Spatial distribution of Lymnaeidae (Mollusca, Basommatophora), intermediate host of Fasciola hepatica Linnaeus, 1758 (Trematoda, Digenea) in Brazil. Rev. Inst. Med. Trop. Sao Paulo, v.56, n. 3, p. 235-252, 2014.

MENDES, E. A. Comportamento e desenvolvimento do F. hepatica (Linnaeus, 1758) de bovinos naturalmente infectados em sagui (Callithrix penicillata) e gerbil (Meriones unguiculatus). 2006. 135f. Dissetação (Mestrado em Parasitologia) - Universidade Federal de Minas Gerais, Belo Horizonte, 2006.

NEVES, D. P.; MELO, A. L.; LINARDI, P. M. et al. Parasitologia Humana. 11. ed. São Paulo: Atheneu, 2005.

NEVES, K. A. L et al. descarte de vísceras de bubalinos abatidos sob inspeção federal na região oeste do Pará, Brasil. Vet. e Zootec. v. 18, n.4, Supl. 3, p. 1138-1141, dez, 2011. OLIVEIRA, A. A.; NASCIMENTO A. S.; SANTOS, T. A. M. et al. Estudo da prevalência e fatores associados à fasciolose no Município de Canutama, Estado do Amazonas, Brasil. Epidemiol. Serv. Saúde. Brasília, v. 16, n. 4, p. 251-259, out/dez, 2007.

PARAENSE, W. L. Lymnaea columella: two new Brazilian localities in the states of Amazonas and Bahia. Mem. Inst. Oswald Cruz. Rio de Janeiro, v.81, n.1, p.121-123, jul/set. 1986.

SEHABIAGUE, M. P. C. Analise do transcriptoma do estágio invasivo do Fasciola hepatica e sua contribuição na compreensão dos mecanismos moleculares envolvidos no processo de infecção. 2010. 135f. Tese (Doutorado em Ciências) - Universidade Federal do Rio Grande do Sul, Porto Alegre, 2010.

SOARES, C. E.; ARAÚJO, J. L.; ARAÚJO, A. M. D. et al. Incidência de Paramphistomum 
ichikawai Funkui 1922 (Trematoda: Paramphistomatidae), em bovinos no Estado do Pará, Brasil. Rev. Bras. Parasitol. Vet. v. 2, n.1, p. 67-69, 1993.

SOUSA, P. B. R.; SILVA, T. T. R.; GOMES, D. L. et al. Pesquisa de estruturas parasitárias na acelga (Brassica rapa) comercializadas em um supermercado de Picos - PI. In: Seminário de Iniciação Científica, 20, 2011, Teresina. Resumos... Teresina: UFPI, 2011.3p.

UFF. Diagnóstico das parasitoses de animais: Departamento de Saúde Coletiva Veterinária e Saúde Pública - Faculdade de Veterinária - Universidade Federal Fluminense. Disponível em: <http://www.uff.br/ diagmsv/index.php?option=com_content $\&$ view $=$ article\&id $=57 \% 3 \mathrm{Afasciola \&}$ catid $=44 \%$ $3 \mathrm{~A}$ helmintos\&ltemid=62>. Acesso em: 25 maio 2015.

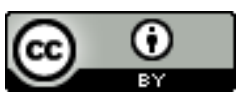

License information: This is an openaccess article distributed under the terms of the Creative Commons Attribution License, which permits unrestricted use, distribution, and reproduction in any medium, provided the original work is properly cited.

Artigo recebido em 22 de fevereiro de 2017.

Avaliado em 09 de agosto de 2017.

Aceito em 06 de setembro de 2017.

Publicado em 22 de setembro de 2017.

\section{Como citar este artigo (ABNT):} OLIVEIRA, Darlan Morais; RESENDE, Patrícia Oliveira. Fasciola hepatica: ecologia e trajetória histórico-geográfica pelo Brasil. Estação Científica (UNIFAP), Macapá, v. 7, n. 2, p. 09-19, maio/ago. 2017. 